\title{
Understanding the Social Networks That Form within the Context of an Obesity Prevention Intervention
}

\author{
Sabina B. Gesell, ${ }^{1}$ Kimberly D. Bess, ${ }^{2}$ and Shari L. Barkin ${ }^{1}$ \\ ${ }^{1}$ Department of Pediatrics, Vanderbilt University School of Medicine, Nashville, TN 37212, USA \\ ${ }^{2}$ Human and Organizational Development, Peabody College, Vanderbilt University, Nashville, TN 37212, USA
}

Correspondence should be addressed to Sabina B. Gesell, sabina.gesell@vanderbilt.edu

Received 28 October 2011; Revised 14 February 2012; Accepted 3 March 2012

Academic Editor: Geoffrey C. Williams

Copyright ( 92012 Sabina B. Gesell et al. This is an open access article distributed under the Creative Commons Attribution License, which permits unrestricted use, distribution, and reproduction in any medium, provided the original work is properly cited.

\begin{abstract}
Background. Antiobesity interventions have generally failed. Research now suggests that interventions must be informed by an understanding of the social environment. Objective. To examine if new social networks form between families participating in a group-level pediatric obesity prevention trial. Methods. Latino parent-preschool child dyads $(N=79)$ completed the 3-month trial. The intervention met weekly in consistent groups to practice healthy lifestyles. The control met monthly in inconsistent groups to learn about school readiness. UCINET and SIENA were used to examine network dynamics. Results. Children's mean age was 4.2 years $(\mathrm{SD}=0.9)$, and $44 \%$ were overweight/obese (BMI $\geq 85$ th percentile). Parents were predominantly mothers $(97 \%)$, with a mean age of 31.4 years $(S D=5.4)$, and $81 \%$ were overweight/obese (BMI $\geq 25)$. Over the study, a new social network evolved among participating families. Parents selectively formed friendship ties based on child BMI z-score, $(t=2.08 ; P<.05)$. This reveals the tendency for mothers to form new friendships with mothers whose children have similar body types. Discussion. Participating in a group-level intervention resulted in new social network formation. New ties were greatest with mothers who had children of similar body types. This finding might contribute to the known inability of parents to recognize child overweight.
\end{abstract}

\section{Background}

Although obesity has stabilized in some US populations, it is still at epidemic proportions, with $31.7 \%$ of all children 219 years of age overweight or obese (BMI $\geq 85$ th percentile) [1]. Anti-obesity efforts often fail $[2,3]$, and exactly why they fail is still unclear. The discouraging results of many studies, including the largest, most rigorous antiobesity trials to be completed, suggest that interventions must be informed by an understanding of the multifactorial forces shaping obesity-related behaviors, including the social environment [3-6].

Social context influences both the routine practice of healthy behaviors and the establishment of norms. Social networks are implicated in both. Social networks differ from social support. Yet, the terms are often used interchangeably. Methodologically, social support is measured from the respondent's perspective to assess the support (e.g., emotional, cognitive, and tangible support) an individual perceives to have, whereas social networks typically measure the presence or absence of friendships and task- or workoriented relationships (which may or may not provide support) and treat the ties themselves as objects of study [7]. Social networks, the complex webs of social relationships and social interactions that connect individuals, have been shown to influence behaviors, whereas social support is generally thought not to influence behavior, but rather is considered a mechanism to cope with challenges and facilitate recovery from illness, injury, or disease [8]. Social network analysis allows us to see the whole group of individuals and their interconnectedness, identifying if new ties are established between people and what type of ties result. Weak ties (e.g., acquaintances) can introduce new ideas into a network, whereas strong ties (e.g., close friendships) can facilitate the dissemination of behaviors through a network. Diffusion studies show that people who are well integrated into a community (have many ties) generally adopt behaviors earlier than those who are less integrated (have fewer ties) $[9,10]$. 
Although social networks exert measurable influence on our health [11-21], most of the work conducted focused on existing social networks. However, given that behavioral intervention trials often occur in a group context [22-24], measuring the development of new social networks and the ties that result is warranted. Once this question is answered, we can determine how to utilize this approach to potentially spread desired behaviors through new networks. Therefore, we set out to examine if families participating in a groupbased obesity intervention form new social ties and, if so, what type of ties result. The effect of the randomized control trial on adiposity measures has been reported elsewhere [25].

\section{Methods}

2.1. Study Sample. Consistent with the Institute of Medicine (IOM) [26] and the Strategic Plan for NIH Obesity Research [27], we implemented a community-based, family-centered, culturally tailored obesity prevention randomized controlled trial (RCT). The intervention was designed for Latino families with preschool aged children and implemented in a public recreation center operated by Parks and Recreation in a neighborhood characterized by relatively high Latino concentration and low socioeconomic status. Study inclusion criteria were (1) self-defined Latino/a, (2) with a child aged 3-5 years, (3) valid phone number, and (4) planning on remaining in the city for 6 months. Participants underwent a 30-minute oral consent process in Spanish before providing written consent. Recruitment occurred between October 2008 and February 2009. The intervention occurred between March and June 2009. The study was approved by the Vanderbilt University Institutional Review Board (IRB no. 080673).

Study randomization occurred after baseline data collection. A total of 106 parent-child dyads were randomized, 92 had exposure to treatment and completed baseline data collection, 79 were retained and provided data at the end of the 3-month intervention period, resulting in an $86 \%$ retention rate for those who attended their first assigned session of the intervention or control conditions (refer to Figure 1). Analysis of RQ(1) included 79 cases; analysis of $\mathrm{RQ}(2)$ included 69 cases.

\subsection{Study Design}

2.2.1. Intervention Condition. The culturally tailored Salud Con La Familia program was designed to improve nutritional family habits, increase physical activity, and decrease screen time. All sessions were conducted in Spanish by the same trained facilitator. To ensure a sizeable treatment dosage [28], the intervention involved a series of 12 (90 min) weekly group sessions. The intervention was based on a best practice program developed by the National Latino Children's Institute (NLCI) [29]. Participants were randomly assigned to small groups (of 6-8 parent-child dyads) that met as a group throughout the study period. At each session, participants were assigned small group activities to practice the skills they needed to apply the information taught (e.g., how to choose appropriate portion sizes; how to be active with children; how to monitor screen time). Leadership roles were rotated through the group with the intention of increasing perceptions of group cohesion [30].

2.2.2. Control Condition. To guard against differential drop out between intervention and control groups, we offered a brief school readiness program as an alternative to the active intervention [31]. Participants met in groups of 812 at 3 times for 60 minutes over the 12 -week study period. The program was based on the Dialogic Reading ModelC.A.R. (comment and wait, ask questions and wait, and respond by adding more), an empirically tested curriculum which teaches parents to read picture books with their children [32]. This model lends itself to all parents, including those with low literacy. The sessions were didactic and conducted in Spanish by the same facilitator who conducted the intervention sessions.

Transportation and childcare for siblings were provided to all study participants to overcome the most frequently cited barriers to study participation [33]. Participants received three small incentives after each wave of data collection (e.g., cutting board), totaling $\$ 60$ per parent-child dyad.

2.2.3. Treatment Fidelity. A treatment fidelity plan was devised following the methodological practices suggested by the Treatment Fidelity Workgroup of the NIH Behavior Change Consortium [34]. The plan included facilitator training; identification of essential treatment components for verification; sampling to ensure treatment consistency; control for differences between interventionists; use of fidelity measures (e.g., frequency of sessions; participation rates). A study team member observed 3 modules of each condition (totaling 25 sessions) and determined that 100\% of the intended key messages were fully discussed, all planned activities had occurred, and intervention content was never delivered during control sessions or vice versa.

2.2.4. Randomization. Participants were randomized in equal proportion to each treatment group by using a computer generated permuted block randomization scheme, with blocks of size 10. A biostatistician generated the randomization list and placed the assignments into nontransparent envelopes, which were sealed and numbered consecutively. After consent, participants received from the research coordinator the next numbered allocation envelope which was opened by the participant. The treatment assignment and number listed on the envelope were recorded by the research coordinator and the participant. Neither researchers nor participants were blinded to participant group allocation.

2.3. Data Collection. All data were collected in Spanish by trained data collectors at the community recreation center at baseline and at completion of the 3 month intervention.

\subsection{Measures}

2.4.1. Social Network. A social network survey was developed to assess change in social relationships over the course of the study period by capturing presence and absence of ties before and after the intervention. The full names of all study 


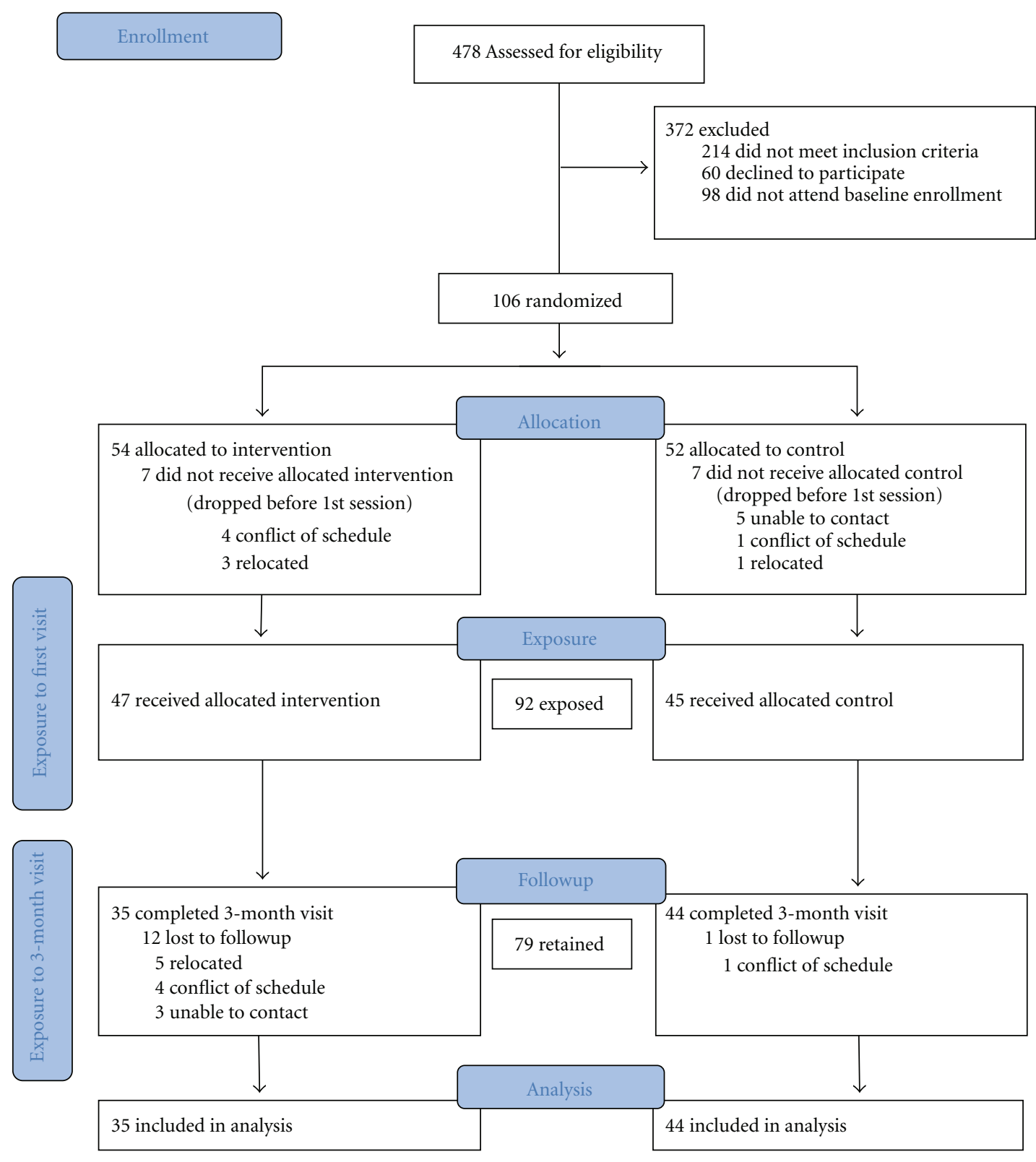

Figure 1: Flow of participants through the trial.

participants were listed on a check box roster. Respondents indicated the type of relationship they had with each other study participant (e.g., no relationship, friend, and acquaintance). Definitions for each type of relationship were provided in the instructions for consistent interpretation of these categories (see the appendix). The whole network was defined as all trial participants, so respondents evaluated their ties to all study participants not just the ones in their own study condition, in order to obtain complete data for analysis.

2.4.2. Height and Weight. Body weight was measured, while wearing light clothing without shoes after voiding, to the nearest $0.1 \mathrm{~kg}$ on a calibrated digital scale (Detecto, Webb City, MO, USA, Model no. 758C). Body height without shoes was measured to the nearest $0.1 \mathrm{~cm}$ with the attached stadiometer.

2.4.3. Body Mass Index (BMI). BMI was calculated (weight $(\mathrm{kg}) /$ height $\left(\mathrm{m}^{2}\right)$ ) [33]. Because the amount of body fat varies for children by age and sex, BMI z-scores were used to provide a standard indicator of relative adiposity [35]. The BMI z-score was computed using the calculator from the Children's Hospital of Philadelphia based on the CDC Growth Charts [36].

2.4.4. Demographics. Parents completed a demographic survey in Spanish. Acculturation was measured using the widely used and previously validated Short-Acculturation Scale for Hispanics (SASH), with internal reliability $r=0.81$ in our 
TABLE 1: Measures of network structure and predicted change.

\begin{tabular}{|c|c|c|}
\hline $\begin{array}{l}\text { Measure of network } \\
\text { structure }\end{array}$ & Definition & $\begin{array}{l}\text { Predicted change } \\
\text { after intervention }\end{array}$ \\
\hline Degree centrality & $\begin{array}{l}\text { Number of ties that an actor has with other actors in } \\
\text { the network. }\end{array}$ & Increase \\
\hline Constraint & $\begin{array}{l}\text { Degree to which extent to which an actor's connections } \\
\text { are to others who are connected to one another. This is } \\
\text { important because less constrained networks would } \\
\text { allow for the possibility of increasing potential } \\
\text { connections through ties with others who are not } \\
\text { already connected to others in ego's network, thereby } \\
\text { enabling exposure to health information and health } \\
\text { behaviors that are flowing through the network. }\end{array}$ & Decrease \\
\hline 2-step reach & $\begin{array}{l}\text { How many people in the network a person could get to } \\
\text { within two links of him/herself, expressed as a } \\
\text { percentage of the total number of people in the } \\
\text { network. This is a good measure of how well any } \\
\text { individual could spread health information or health } \\
\text { behaviors through the network by reaching out to } \\
\text { friends and friends-of-friends. }\end{array}$ & Increase \\
\hline Density & $\begin{array}{l}\text { The number of ties among people in the network } \\
\text { expressed as a percentage of all possible ties. If every } \\
\text { person is tied directly with every other person the } \\
\text { density is } 100 \% \text {. Increased density would allow for } \\
\text { accelerated flow of desired health information or health } \\
\text { behaviors through the network. }\end{array}$ & Increase \\
\hline
\end{tabular}

sample. [37] The SASH asks respondents to indicate the language they read and speak, use at home, think in, and use among friends (Spanish only, Spanish more than English, Spanish and English equally, English more than Spanish, and English only). Scores range from 1 to 5 ; a score $<2.99$ indicates a low level of acculturation.

2.5. Statistical Analysis. To answer RQ(1) we computed three ego-network-level measures (degree centrality, constraint, and 2-step reach) and one whole-network-level measure (density) of structure to determine if new relationships developed during the intervention period (definitions of terms noted in Table 1). T-tests were performed to compare intervention and control group using UCINET [38] and a bootstrap method in which observations are not assumed to be independent [39]. We created maps of each network in NetDraw [38].

To answer RQ(2), we used SIENA [40-42] to test for underlying network tendencies in network dynamics and selection effects. SIENA begins with the assumption of a continuous time parameter [43]. This provides the foundation for the assumption of a Markov process in which each subsequent change in the network is dependent upon previous network conditions. That is, newly formed network ties are dependent on the existing network structure, or as Snijders et al. [42] suggest "the total network structure is the social context that influences the probabilities of its own change" (p. 6). Finally, in this process it is assumed that actors have the possibility of forming new ties, maintaining ties, or dropping existing ties. We treated BMI as a constant covariate and controlled for several commonly observed tendencies in network dynamics: outdegree, reciprocity, and transitivity (definitions of terms noted in Table 2). In two separate models, we tested (a) whether parents tend to form ties with other parents who have a similar BMI, and (b) whether parents tend to form ties with other parents who have children with a similar BMI.

\section{Results}

3.1. Sample Description. Approximately 6 weeks passed between baseline data collection and the first intervention and control sessions, and in this time 14 randomized participants dropped from the study pool leaving a sample of 92 dyads exposed to intervention or control conditions (Figure 1). As Figure 1 shows, the attrition rate from initial exposure to 3 -month followup was lower in the control group (15\%) than in the intervention group $(36 \%)$. There were no significant demographic or anthropometric differences at baseline between dyads who completed the 3-month follow-up data collection $(n=75)$ and randomized participants who did not finish the study ( $n=27$; results available upon request). Among the 35 dyads in the intervention group for which we have 3 -month data, the median number of sessions attended was 7 out of the 12 offered.

The majority of participating parents were mothers, first-generation Mexican immigrants, with low levels of acculturation (mean SASH score 1.4) and education (25\% of our sample had less than an 8th grade education). Children were typically US-born. Eighty-one percent of participating parents were overweight/obese $\left(\mathrm{BMI} \geq 25 \mathrm{~kg} / \mathrm{m}^{2}\right)$ as well as $42 \%$ of children (BMI percentile $\geq 85 \%$ ). The groups 
TABle 2: Network effects included in the model.

\begin{tabular}{ll}
\hline Network effects & Definition \\
\hline Outdegree & $\begin{array}{l}\text { Ties leaving an actor (number of people marked as friends). Measure } \\
\text { of the level of activity in the network. } \\
\text { Reciprocity is the extent to which ties are reciprocated between } \\
\text { actors. Over time if A selects B, then B will reciprocate and select A, } \\
\text { or A will drop his/her ties to B. There is an equilibrium tendency } \\
\text { toward dyadic relationships to be either reciprocated or null. }\end{array}$ \\
$\begin{array}{l}\text { Reciprocity } \\
\text { (transitive ties } \\
\text { and } 3 \text { cycles) }\end{array}$ & $\begin{array}{l}\text { The tendency for a friend of a friend to become a friend. } \\
\text { Similarity }\end{array}$ \\
& $\begin{array}{l}\text { Actors tend to form relationships with others who are similar to them } \\
\text { in particular ways. Also termed homophily effect or more colloquially } \\
\text { known as the idea that "birds of a feather flock together." }\end{array}$ \\
\hline
\end{tabular}

of dyads who completed the intervention and control conditions did not significantly differ on demographics or anthropometric measurements at baseline (Table 3).

\subsection{RQ (1): Social Network Structure Change. Although} given the option of indicating type of tie as friendship, acquaintance or transactional partner, no participant indicated acquaintance or transactional partner ties. Thus, the analysis is focused on friendship ties. At baseline, there were no significant differences between intervention and control groups in the four measures of network structure (degree centrality, constraint, two-step reach, and density). After the intervention, all network measures had changed in the predicted directions, in both intervention and control group, and all changes were significantly greater in the intervention group compared to the control group (Table 4).

3.2.1. Degree Centrality. The number of social ties people had with others in the network, averaged 1.5 at baseline. At study conclusion, intervention group members had developed more friendship ties compared to the control group (6.4 ties versus 3.9 ties).

3.2.2. Constraint. The degree to which a person's ties are with others who are connected to each other, declined at the end of the study period, in both groups, but significantly more so in the intervention group. This means that intervention group members not only had more ties, but also those ties were less likely to be people who were already friends with each other.

3.2.3. Two-Step Reach. The proportion of people in the network that any individual could reach through their friends and the friends of their friends, increased in both groups but significantly more so for the intervention group. At the beginning of the intervention, any person in the intervention group could have reached only $3 \%$ of the other group participants, whereas after the intervention they could have reached $32 \%$ of the other group members.

Although density more than doubled in the intervention group compared to the control group, at study completion the intervention group network was still a sparse network with fairly low density. Graphic representation of these network changes is given in Figure 2.

\section{3. $R Q(2)$ : Characteristic of New Social Ties}

3.3.1. Basic Network Effects. The Jaccard index, which measures how much change (related to ties created and ties dropped) occurs between points of data collection, was .256 [43]. Although a Jaccard index of .3 is recommended for discerning structural equivalence sets, in this study the slightly lower Jaccard index is considered acceptable given that the program brought together many mothers previously unknown to one another [43]. The model convergence was good as indicated by all t-ratio diagnostics being close to zero.

The negative parameter for outdegree was expected because most observed networks are sparse with densities well below .50. This makes intuitive sense in terms of the limit on the number of ties that any one actor can maintain and the potential costs that might be incurred with the formation of new ties [42].

The positive reciprocity parameter indicates that over time if person A selects person $B$ as a friend, then person $B$ will select person $A$, or person $A$ will drop his/her tie to person $\mathrm{B}$.

The significant positive transitive closure effect suggests that there is a tendency for a friend of a friend to become a friend. The positive and significant effect for 3 cycles also suggests that there is a tendency toward localized closure but the positive parameter indicates that this tendency is not toward a hierarchical structure, but rather toward localized exchange and generalized reciprocity [42]. That is, the positive 3-cycle effect represents a pattern in which person A selects person $B$, person $B$ selects person $C$, and person $\mathrm{C}$ selects person $\mathrm{A}$. The presence of this pattern indicates that no single actor is privileged as being chosen above others. The tendency toward closure suggested by the positive transitive ties and 3-cycle effects at first glance may seem at odds with the bivariate finding of decreased constraint noted above. This finding can be reconciled in light of the significant increase in density of the network from pre- to post-test. Constraint is a relative measure based on the extent to which actors have transitive or intransitive ties. With the increase in the number of new ties in the network, it would be 
TABLE 3: Baseline demographic characteristics of latino parent-child dyads $(N=79)$.

\begin{tabular}{|c|c|c|c|c|c|}
\hline \multirow{2}{*}{$\begin{array}{l}\text { Domain } \\
\text { Child }\end{array}$} & \multicolumn{2}{|c|}{ Control } & \multicolumn{2}{|c|}{ Intervention } & \multirow[t]{2}{*}{$P$-value ${ }^{1}$} \\
\hline & Mean & S.D. & Mean & S.D. & \\
\hline Age & 4.1 & 0.9 & 4.2 & 0.9 & 0.85 \\
\hline Gender ( $\%$ female) & 54.6 & & 45.7 & & 1.00 \\
\hline BMI z-score & 1.0 & 1.2 & 0.8 & 1.3 & 0.70 \\
\hline Waist circumference & 56.7 & 7.3 & 55.7 & 5.8 & 0.48 \\
\hline Body fat percentage & 34.0 & 8.2 & 34.1 & 9.9 & 0.97 \\
\hline \multicolumn{6}{|l|}{ BMI percentile ${ }^{2}$} \\
\hline Underweight $(\mathrm{BMI}<5 \%)$ & $5 \%$ & & $3 \%$ & & \\
\hline Normal weight $(\mathrm{BMI} \geq 5 \%<85 \%)$ & $45 \%$ & & $62 \%$ & & \\
\hline Overweight $(\mathrm{BMI} \geq 85 \%<95 \%)$ & $25 \%$ & & $15 \%$ & & \\
\hline Obese (BMI $\geq 95 \%)$ & $25 \%$ & & $20 \%$ & & \\
\hline \multicolumn{6}{|l|}{ Adult } \\
\hline Age & 32.3 & 5.7 & 30.7 & 6.0 & 0.22 \\
\hline Acculturation $^{3}$ & 1.4 & 0.6 & 1.3 & 0.5 & 0.55 \\
\hline Relationship to child ${ }^{4}$ & 93.2 & & 94.3 & & \\
\hline \multicolumn{6}{|l|}{ Maternal education ${ }^{5}$} \\
\hline$<$ High school & $63.6 \%$ & & $65.7 \%$ & & \\
\hline$\geq \mathrm{HS}<$ college & $27.3 \%$ & & $31.4 \%$ & & \\
\hline$\geq$ College & $9.1 \%$ & & $2.9 \%$ & & \\
\hline $\mathrm{BMI}^{6}$ & 30.4 & 5.8 & 29.0 & 5.3 & 0.27 \\
\hline Waist circumference & 99.4 & 16.3 & 100.8 & 21.4 & 0.75 \\
\hline Body fat percentage & 40.3 & 7.3 & 40.0 & 5.8 & 0.85 \\
\hline \multicolumn{6}{|l|}{ BMI category ${ }^{7}$} \\
\hline Underweight $(\mathrm{BMI}<18.5)$ & $0 \%$ & & $0 \%$ & & \\
\hline Normal $(\mathrm{BMI} \geq 18.5<25)$ & $18.2 \%$ & & $20.0 \%$ & & \\
\hline Overweight $(\mathrm{BMI} \geq 25<30)$ & $34.1 \%$ & & $45.7 \%$ & & \\
\hline Obese $(\mathrm{BMI} \geq 30)$ & $47.7 \%$ & & $34.3 \%$ & & \\
\hline
\end{tabular}

${ }^{1} T$-tests were used except for categorical variables (those reported only in percentages), where exact Fisher tests were used.

${ }^{2}$ Percentage of children by CDC weight status categories defined by BMI percentile for age. Percentages may not sum to $100 \%$ due to rounding.

${ }^{3}$ Short-Acculturation Scale for Hispanics (SASH).

${ }^{4}$ Percentage of respondents who are mothers.

${ }^{5}$ Percentage of adults by education category in each group.

${ }^{6}$ Usual measure of BMI $\left(\mathrm{kg} / \mathrm{cm}^{2}\right)$.

${ }^{7}$ Percentage of adults by BMI category in each group: underweight category is omitted. The BMI categories are defined using the BMI measure $\left(\mathrm{kg} / \mathrm{cm}^{2}\right)$ for the adult.

reasonable to see an increase in transitivity even if the ratio of transitive to intransitive ties has changed. A visual inspection of Figure 2 demonstrates the logic of this explanation. One can see that the overall number of participants that are active in the network has increased (in the pretest networks isolates are not depicted). On the periphery of both posttest networks one can see that many participants only have one or two intransitive ties, contributing to decreased constraint. Yet, at the same time, one can see an increased number of triangles in the posttest networks in comparison to the pretest network, indicating the tendency toward transitive closure.

3.3.2. Selection Effects. The results suggest a tendency for parents to form new friendship ties with other parents whose child's BMI z-score is similar to their own child's BMI
Z-score, $(t=2.08, P<.05$; Table 5$)$. There was no significant selection effect for maternal BMI in the formation of new social ties; that is, overweight mothers were not more likely to select overweight mothers as friends $(P>.05)$.

\section{Discussion}

Several research teams have empirically linked social network structures to adult and adolescent obesity $[13,15,21]$. To date, very little research elucidates the network context of obesity among children. While many obesity interventions occur in a group setting, underlying group structure and group processes are not documented in the scientific literature. Our research demonstrates that a new social network evolved among families participating in a pediatric obesity group-based prevention trial. Moreover, these new social 
Before intervention network

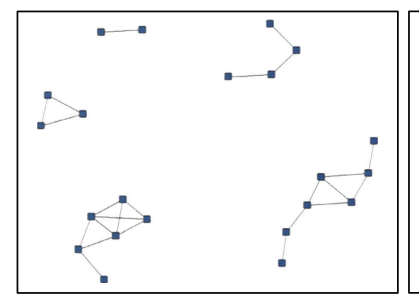

Control

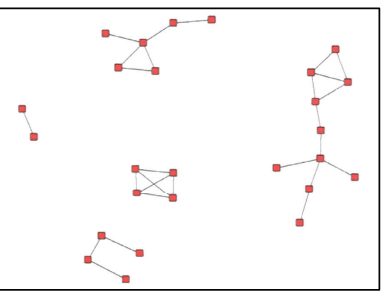

Intervention

(a)

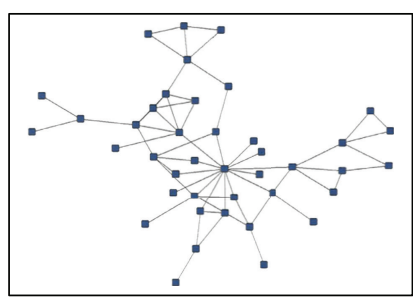

Control
After intervention network

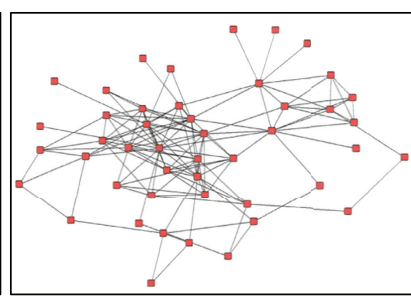

Intervention

(b)

Figure 2: Mapping of social network changes over 3-month intervention. Each graph shows the study participants who have social ties with other study participants. These maps illustrate several points: First, some study participants already knew each other at baseline. This reflects the fact that the most effective recruitment strategy in this Latino population was word of mouth referrals. Importantly, there were no differences in preexisting network ties between control and intervention groups. Second, while some study participants already knew other study participants at baseline, half did not, and thus are not shown here, reflecting the average number of ties of 1.5 at baseline. Third, after the intervention, each group increased in the number of participants who had ties with others in the group.

TABLE 4: T-Tests of goup differences related to individual network attributes.

\begin{tabular}{|c|c|c|c|c|c|}
\hline \multicolumn{6}{|c|}{ Mean change in individual network attributes } \\
\hline & & $\begin{array}{c}\text { Intervention } \\
\text { Group }(n=35)\end{array}$ & $\begin{array}{l}\text { Control Group } \\
\quad(n=44)\end{array}$ & Difference & $P$ value \\
\hline \multirow{2}{*}{ Degree Centrality } & Before & 1.52 & 1.45 & 0.07 & 0.847 \\
\hline & After & 6.41 & 3.89 & 2.52 & 0.006 \\
\hline \multirow{2}{*}{ Constraint } & Before & 0.85 & 0.90 & 0.05 & 0.127 \\
\hline & After & 0.52 & 0.68 & 0.16 & 0.011 \\
\hline \multirow{2}{*}{ 2-step reach } & Before & 3.08 & 2.81 & 0.27 & 0.675 \\
\hline & After & 32.53 & 23.99 & 8.54 & 0.014 \\
\hline
\end{tabular}

TABle 5: Parameter estimates.

\begin{tabular}{lccc}
\hline Parameter & Estimates & $\begin{array}{c}\text { Standard } \\
\text { errors }\end{array}$ & $t$-statistic \\
\hline Basic network effects & & & \\
$\quad$ outdegree (density) & -2.1628 & 0.1944 & -11.1255 \\
$\quad$ Reciprocity & 2.0274 & 0.2817 & 7.1970 \\
$\quad 3$ cycles & 0.8184 & 0.2898 & 2.8240 \\
$\quad$ Transitive ties & 1.3133 & 0.2198 & 5.9968 \\
\hline Selection effects & & & \\
$\quad$ Similarity_Child & 1.2742 & 0.6133 & 2.08 \\
$\quad$ BMI Z-score & & & \\
\hline
\end{tabular}

ties formed in a predictable manner, with mothers forming friendship ties with other mothers' who had children of similar body type.

Normative expectations are perpetuated by the company we keep. If parents see predominately overweight children, this becomes the new normal. Social norms are thought to at least partially account for the clustering of health behaviors among social contacts $[12,13,44]$. Leahey et al. presented the first research to explicitly test this assumption. Their findings suggest that social norms specific to one's social network (subjective norms) influence weight more than broad societal level social norms (injunctive norms) [45]. Subsequently, social network phenomena might explain some of the factors that underlie the misperception of body size and the social context in which they develop and are maintained. Parental misperceptions of child weight status are well documented, even among parents of preschool aged children [46, 47], and affect the likelihood that parents will take action to ameliorate their child's weight problem [48].

We did not find overweight mothers to be more likely to select other overweight mothers as friends. Our null result is likely due to the low variability in our sample (more than $90 \%$ of participating mothers were obese) and small sample size for detecting selection effects. Others have clearly shown that adult and adolescent friendships cluster on the basis of weight status $[6,13,15,45]$.

There is evidence that social networks can spread positive health behaviors, such as smoking cessation, contraception use, and reduced drug and alcohol use [12, 15-17, 44]. Such findings raise the question of whether social networkseither existing or newly constructed-might also spread obesity-protecting behaviors, such as physical activity, consumption of fruits and vegetables, or sleep hygiene. This research lays the groundwork for understanding that new social networks can be formed in group-level interventions. Prudent next steps would be to examine the extent to which novel interventions could build new social networks to intentionally spread health behaviors. To explore such effects, 
TABle 6: Please place a check in the box next to each name describing the relationship you have with that person. For each name, indicate only your relationship and leave all other options for that person blank.

\begin{tabular}{lccccc}
\hline Participant name & Myself & Family member & Friend & $\begin{array}{c}\text { Transactional } \\
\text { partner }\end{array}$ & Acquaintance \\
\hline Ana Alvarez & $\square$ & $\square$ & $\square$ & $\square$ & $\square$ \\
Blanca Bins & $\square$ & $\square$ & $\square$ & $\square$ & $\square$ \\
Camila Cruz & $\square$ & $\square$ & $\square$ & $\square$ & $\square$ \\
Daisy Diaz & $\square$ & $\square$ & $\square$ & $\square$ & $\square$ \\
$\ldots \ldots$ & $\square$ & $\square$ & $\square$ & $\square$ & $\square$ \\
$\ldots \ldots$ & $\square$ & $\square$ & $\square$ & $\square$ \\
\hline
\end{tabular}

future health studies should include social network data. This study is a necessary first step in using social network analysis to strengthen group-based behavioral interventions that can be utilized in trials that aim to prevent or treat obesity.

\section{Future Research}

Given that many obesity prevention and early intervention behavioral trials utilize group settings, understanding new network formation could influence future trial design and implementation. Future group-based interventions might leverage the observed selection effect (mothers forming friendships based on child BMI) to intentionally increase group cohesion which, under favorable network conditions, may accelerate the uptake of prohealth knowledge, attitudes, and behavior across the whole network [11]. Alternatively, the observed selection effect might make it harder to intervene in individual behavior, in which case it would be prudent to counter the network effect by assigning parent-child dyads of varying BMI categories to work in groups together so that a high BMI is not seen as normative. Building on these findings and computer simulations of large social networks conducted by Bahr et al. [6], allowing parents to self-select partners in small group activities will likely lead them to cluster in social groups according to child BMI, and if unrestrained, current social forces will likely drive their children toward increasing obesity. It is also possible that just making parents aware of the tendency for mothers to selectively befriend mothers whose children have similar BMIs might be a useful way to correct body size and adiposity perceptions.

\section{Study Limitations}

Social ties in the control condition increased despite limited social interaction during the study period. This could reflect the fact that our study population, with low acculturation, feels socially isolated and yearns for connections with other Latinos in the same stage of life. One of the strengths of this study is the inclusion of rigorous network control variables in the modeling to rule out alternative explanations of our findings. The analysis cannot, however, rule out the effects of other individual differences in propensity to connect with others. We do not know if the new social ties were strong enough to withstand the test of time. Testing for influence effects was outside the scope of this paper. The evaluation of whether newly constructed social networks influenced health behaviors (i.e., physical activity) was untestable due to missing data. The analysis of whether newly constructed social networks influenced health outcomes (i.e., BMI) yielded nonsignificant results. These questions can be examined with additional waves of data collection and larger samples with complete data. Only friendship ties were reported (no acquaintance or transactional partner ties). It is unclear if this finding is indicative of the strength of the groups or an artifact of how the question was asked. We did not collect any process measures of role rotation during the intervention sessions, or a measure of perceived group cohesion. As with most community studies, we had attrition over the course of the intervention and note that this was greater in the intervention group than the control group. This could have biased our findings, but that is unlikely given that the noncompleters had similar initial anthropometric data to the completers.

\section{Conclusion}

The present study found that (1) a new social network can develop as a result of participating in an obesity prevention intervention in a group setting, and (2) study participants selectively form social ties based on their children's weight status. These findings should be taken into consideration as we develop pediatric obesity group-based intervention strategies that capitalize on the social environment.

\section{Appendix}

\section{Social Network Instrument (English Translation)}

Instructions. Listed below are the names of participants in The Salud Con La Familia Program at the Coleman Community Center. Please indicate your relationship to the participants.

By "Family Member," we mean a blood relation or family link (such as a sister, cousin, or sister-in-law).

By "Friend," we mean someone with whom you have close relationship or with whom you share feelings.

By “Transactional partner," we mean someone who provides a favor or service to you or you provide for them (such as someone with whom you arrange 
transport or childcare or a search for jobs or appointments, an employer, employee, client).

By "Acquaintance," we mean someone you know but who does not directly influence your daily life (such as a neighbor or colleague at work or church, whom you may greet or know by name but is neither a friend nor a person with whom you have dealings).

Please see Table 6 for details.

\section{Conflict of Interests}

The authors declare that they have no conflict of interests.

\section{Acknowledgments}

The authors thank Tokesha Warner for project management; Juan Escarfuller for intervention implementation; Josie Garza of the National Latino Children's Institute for curricular input; and Metropolitan Government of Nashville \& Davidson County Parks and Recreation Department leaders Roy Wilson, Paul Widman, Stevon Neloms, and Tommy Lynch for their support throughout study implementation and partnership. This study was funded by the State of Tennessee Project Diabetes Implementation Grant (GR-0925517-00, Barkin (PI)) and the Vanderbilt CTSA grant (NCRR/NIH 1 UL1 RR024975, Bernard (PI)). S.B. Gesell was supported by the American Heart Association Clinical Research Grant Program (09CRP2230246). ClinicalTrials.gov Identifier: NCT00808431. Vanderbilt IRB no. 080673.

\section{References}

[1] C. L. Ogden, M. D. Carroll, L. R. Curtin, M. M. Lamb, and K. M. Flegal, "Prevalence of high body mass index in US children and adolescents, 2007-2008," Journal of the American Medical Association, vol. 303, no. 3, pp. 242-249, 2010.

[2] R. W. Jeffery and J. Linde, "Population approaches to obesity prevention," in Obesity Prevention and Public Health, D. Crawford and R. W. Jeffery, Eds., Oxford University Press, New York, NY, USA, 2005.

[3] L. L. Birch and A. K. Ventura, "Preventing childhood obesity: what works," International Journal of Obesity, vol. 33, no. 1, pp. S74-S81, 2009.

[4] C. B. Ebbeling and D. S. Ludwig, "Pediatric obesity prevention initiatives: more questions than answers," Archives of Pediatrics and Adolescent Medicine, vol. 164, no. 11, pp. 1067-1069, 2010.

[5] L. H. Epstein and B. H. Wrotniak, "Future directions for pediatric obesity treatment," Obesity, vol. 18, supplement 1 , pp. S8-S12, 2010.

[6] D. B. Bahr, R. C. Browning, H. R. Wyatt, and J. O. Hill, "Exploiting social networks to mitigate the obesity epidemic," Obesity, vol. 17, no. 4, pp. 723-728, 2009.

[7] K. P. Smith and N. A. Christakis, "Social networks and health," Annual Review of Sociology, vol. 34, pp. 405-429, 2008.

[8] T. Valente, Personal Communication, 2011.

[9] E. M. Rogers and D. L. Kincaid, Communication Networks: Toward a New Paradigm for Research, Free Press, New York, NY, USA, 1981.

[10] J. S. Coleman, E. Katz, and H. Menzel, Medical Innovation: A Diffusion Study, Bobs Merrill, New York, NY, USA, 1966.
[11] T. W. Valente, Social Networks and Health: Models, Methods, and Applications, Oxford University Press, New York, NY, USA, 2010.

[12] N. A. Christakis and J. H. Fowler, "The collective dynamics of smoking in a large social network," New England Journal of Medicine, vol. 358, no. 21, pp. 2249-2258, 2008.

[13] N. A. Christakis and J. H. Fowler, "The spread of obesity in a large social network over 32 years," New England Journal of Medicine, vol. 357, no. 4, pp. 370-379, 2007.

[14] S. Cohen, W. J. Doyle, D. P. Skoner et al., "Social ties and susceptibility to the common cold," Journal of the American Medical Association, vol. 277, no. 24, pp. 1940-1944, 1997.

[15] T. W. Valente, K. Fujimoto, C. P. Chou, and D. Spruijt-Metz, "Adolescent affiliations and adiposity: a social network analysis of friendships and obesity," Journal of Adolescent Health, vol. 45, no. 2, pp. 202-204, 2009.

[16] T. W. Valente, S. C. Watkins, M. N. Jato, A. Van Der Straten, and L. P. M. Tsitsol, "Social network associations with contraceptive use among Cameroonian women in voluntary associations," Social Science and Medicine, vol. 45, no. 5, pp. 677687, 1997.

[17] T. W. Valente, A. Ritt-Olson, A. Stacy, J. B. Unger, J. Okamoto, and S. Sussman, "Peer acceleration: effects of a social network tailored substance abuse prevention program among high-risk adolescents," Addiction, vol. 102, no. 11, pp. 1804-1815, 2007.

[18] J. G. Trogdon, J. Nonnemaker, and J. Pais, "Peer effects in adolescent overweight," Journal of Health Economics, vol. 27, no. 5, pp. 1388-1399, 2008.

[19] T. J. Halliday and S. Kwak, "Weight gain in adolescents and their peers," Economics and Human Biology, vol. 7, no. 2, pp. 181-190, 2009.

[20] S. C. Mednick, N. A. Christakis, and J. H. Fowler, "The spread of sleep loss influences drug use in adolescent social networks," PloS One, vol. 5, no. 3, article e9775, 2010.

[21] K. de la Haye, G. Robins, P. Mohr, and C. Wilson, "Obesityrelated behaviors in adolescent friendship networks," Social Networks, vol. 32, no. 3, pp. 161-167, 2010.

[22] T. N. Robinson, "Behavioural treatment of childhood and adolescent obesity," International Journal of Obesity, vol. 23, supplement 2, pp. S52-S57, 1999.

[23] R. C. Klesges, E. Obarzanek, S. Kumanyika et al., "The Memphis Girls' health Enrichment Multi-site Studies (GEMS): an evaluation of the efficacy of a 2-year obesity prevention program in African American girls," Archives of Pediatrics and Adolescent Medicine, vol. 164, no. 11, pp. 1007-1014, 2010.

[24] T. N. Robinson, D. M. Matheson, H. C. Kraemer et al., "A randomized controlled trial of culturally tailored dance and reducing screen time to prevent weight gain in low-income African American girls: stanford GEMS," Archives of Pediatrics and Adolescent Medicine, vol. 164, no. 11, pp. 995-1004, 2010.

[25] S. L. Barkin, S. B. Gesell, E. K. Po'e, J. Escarfuller, and T. Tempesti, "Culturally tailored, family-centered, short-term behavioral intervention and BMI in Latino American preschool children," Pediatrics.

[26] Institute of Medicine. Committee on Progress in Preventing Childhood Obesity, Progress in Preventing Childhood Obesity: How Do We Measure Up, The National Academies Press, 2006.

[27] U.S. Department of Health and Human Services, Strategic Plan for NIH Obesity Research: A Report of the NIH Obesity Research Task Force, National Institutes of Health, Rockville, Md, USA, 2004.

[28] C. D. Summerbell, E. Waters, L. D. Edmunds, S. Kelly, T. Brown, and K. J. Campbell, "Interventions for preventing obesity in children," Cochrane Database of Systematic Reviews, no. 3, Article ID CD001871, 2005. 
[29] National Latino Children's Institute, "Salsa, Sabor y Salud. Healthy Lifestyles for Latino Families," 2004, http://www.nlci .org/salsa/indexSSS.htm.

[30] M. Salo, "The relation between sociometric choices and group cohesion," Tech. Rep. 1193, United States Army Research Institute for the Behavioral and Social Sciences, 2006.

[31] S. Gesell, D. Wallace, T. Tempesti, V. Hux, and S. Barkin, "Increasing Latino parents' verbal interactions with their preschool-aged children," ISRN Education, vol. 2012, Article ID 652406, 9 pages, 2012.

[32] Washington Learning Systems, "Language is the Key: A Program for Building Language and Literacy in Early Childhood," 2006, http://www.edgateway.net/cs/es/view/lwe/93615.

[33] E. G. Eakin, S. S. Bull, K. Riley, M. M. Reeves, S. Gutierrez, and P. McLaughlin, "Recruitment and retention of Latinos in a primary care-based physical activity and diet trial: the resources for health study," Health Education Research, vol. 22, no. 3, pp. 361-371, 2007.

[34] A. J. Bellg, B. Resnick, D. S. Minicucci et al., "Enhancing treatment fidelity in health behavior change studies: best practices and recommendations from the NIH Behavior Change Consortium," Health Psychology, vol. 23, no. 5, pp. 443-451, 2004.

[35] T. J. Cole, M. S. Faith, A. Pietrobelli, and M. Heo, "What is the best measure of adiposity change in growing children: BMI, BMI \%, BMI z-score or BMI centile?” European Journal of Clinical Nutrition, vol. 59, no. 3, pp. 419-425, 2005.

[36] Children's Hospital of Philadelphia, "Body Mass Index and ZScore Calculation in Children," 2010, http://stokes.chop.edu/ web/zscore/.

[37] G. Marín, F. Sabogal, B. V. Marín, R. Otero-Sabogal, and E. J. Perez-Stable, "Development of a short acculturation scale for Hispanics," Hispanic Journal of Behavioral Sciences, vol. 9, pp. 183-205, 1987.

[38] S. P. Borgatti, M. G. Everett, and L. C. Freeman, Ucinet for Windows: Software for Social Network Analysis, Analytic Technologies, Harvard, Mass, USA, 2002.

[39] T. A. B. Snijders and S. P. Borgatti, "Non-parametric standard errors and tests for netowrk statisitics," Connections, vol. 22, no. 2, pp. 161-170, 1999.

[40] T. A. B. Snijders, "The statistical evaluation of social network dynamics," Sociological Methodology, vol. 31, no. 1, pp. 361395, 2001.

[41] T. A. B. Snijders, Models for Longitudinal Network Data, Edited by J. S. Carrington and S. Wasserman, Cambridge University Press, New York, NY, USA, 2005.

[42] T. Snijders, C. Steglich, and M. Schweinberger, "Modeling the co-evolution of networks and behavior," in Longitudinal Models in the Behavioral and Related Sciences, K. van Montfort, H. Oud, and A. Satorra, Eds., Lawrence Erlbaum, Mahwah, NJ, USA, 2007.

[43] T. A. B. Snijders, G. G. van de Bunt, and C. E. G. Steglich, "Introduction to stochastic actor-based models for network dynamics," Social Networks, vol. 32, no. 1, pp. 44-60, 2010.

[44] J. N. Rosenquist, J. Murabito, J. H. Fowler, and N. A. Christakis, "The spread of alcohol consumption behavior in a large social network," Annals of Internal Medicine, vol. 152, no. 7, pp. 426-433, 2010.

[45] T. M. Leahey, J. G. Larose, J. L. Fava, and R. R. Wing, "Social influences are associated with bmi and weight loss intentions in young adults," Obesity, vol. 19, no. 6, pp. 1157-1162, 2011.

[46] J. Doolen, P. T. Alpert, and S. K. Miller, "Parental disconnect between perceived and actual weight status of children: a metasynthesis of the current research," Journal of the American Academy of Nurse Practitioners, vol. 21, no. 3, pp. 160-166, 2009.
[47] H. Oude Luttikhuis, L. Baur, H. Jansen et al., "Interventions for treating obesity in children," Cochrane Database of Systematic Reviews, no. 1, Article ID CD001872, 2009.

[48] E. M. Taveras, K. H. Hohman, S. N. Price et al., "Correlates of participation in a pediatric primary care-based obesity prevention intervention," Obesity, vol. 19, no. 2, pp. 449-452, 2011. 


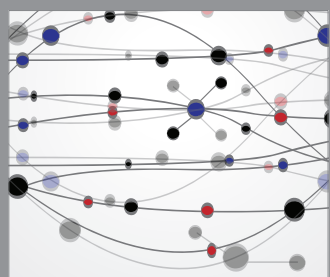

The Scientific World Journal
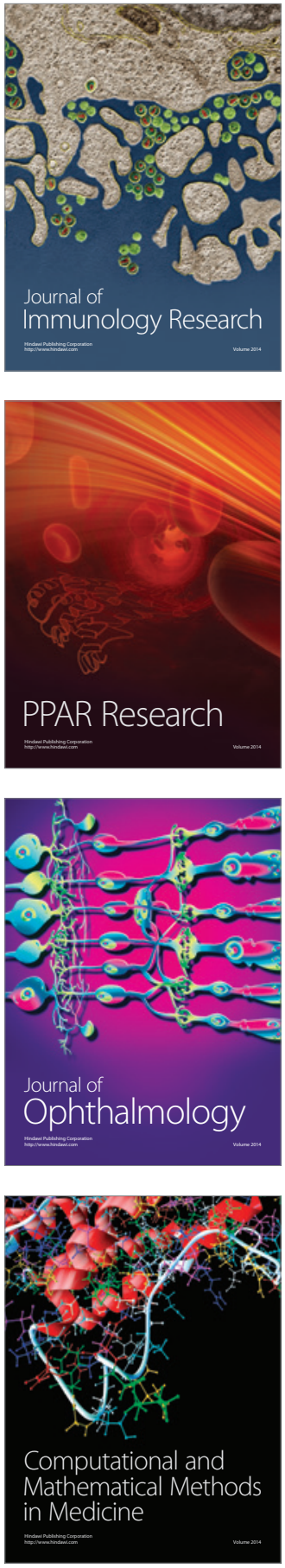

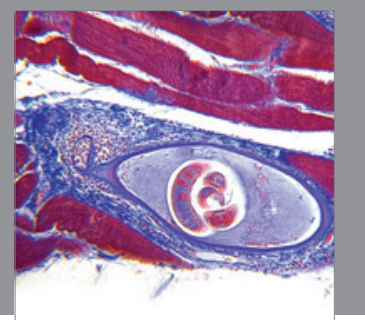

Gastroenterology

Research and Practice
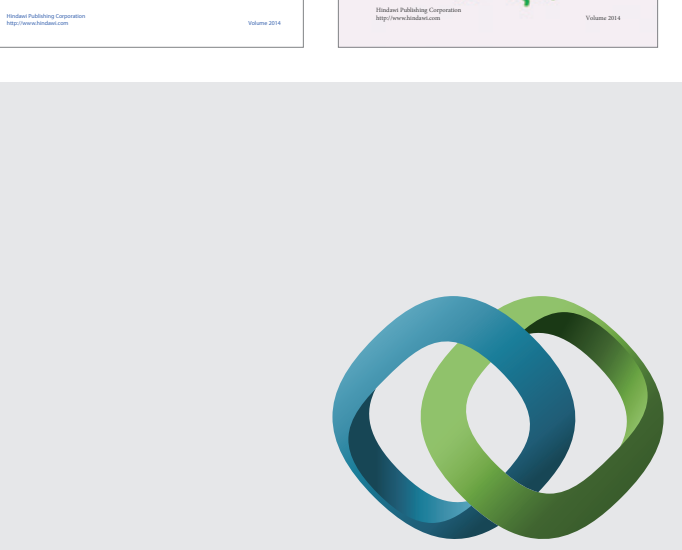

\section{Hindawi}

Submit your manuscripts at

http://www.hindawi.com
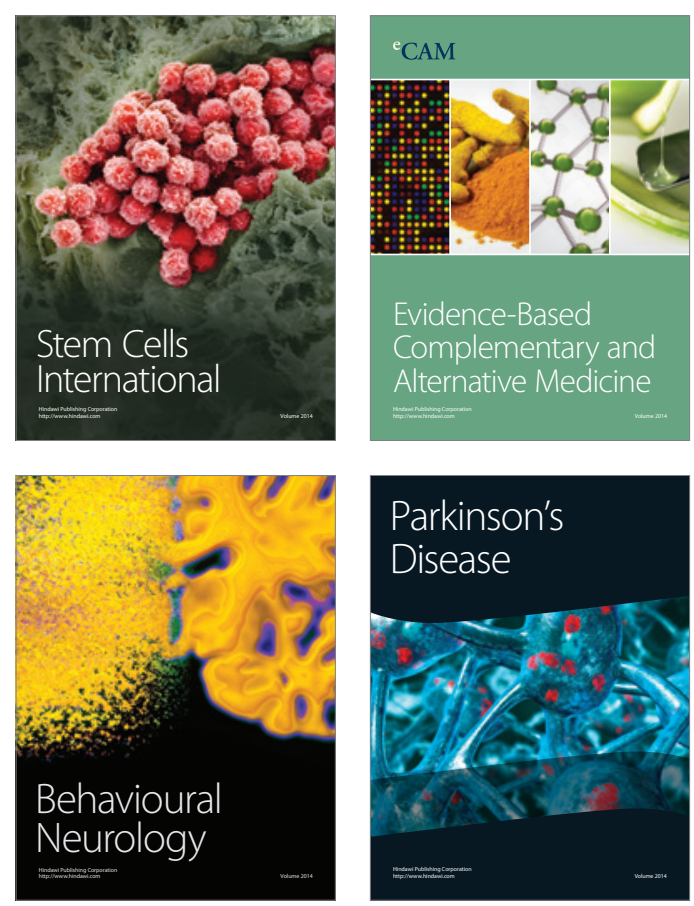

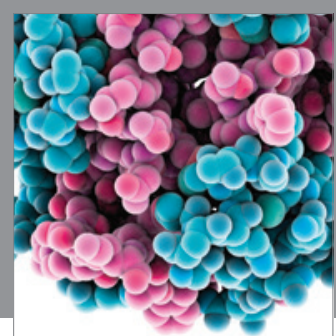

Journal of
Diabetes Research

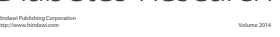

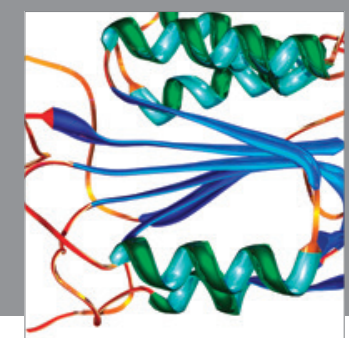

Disease Markers
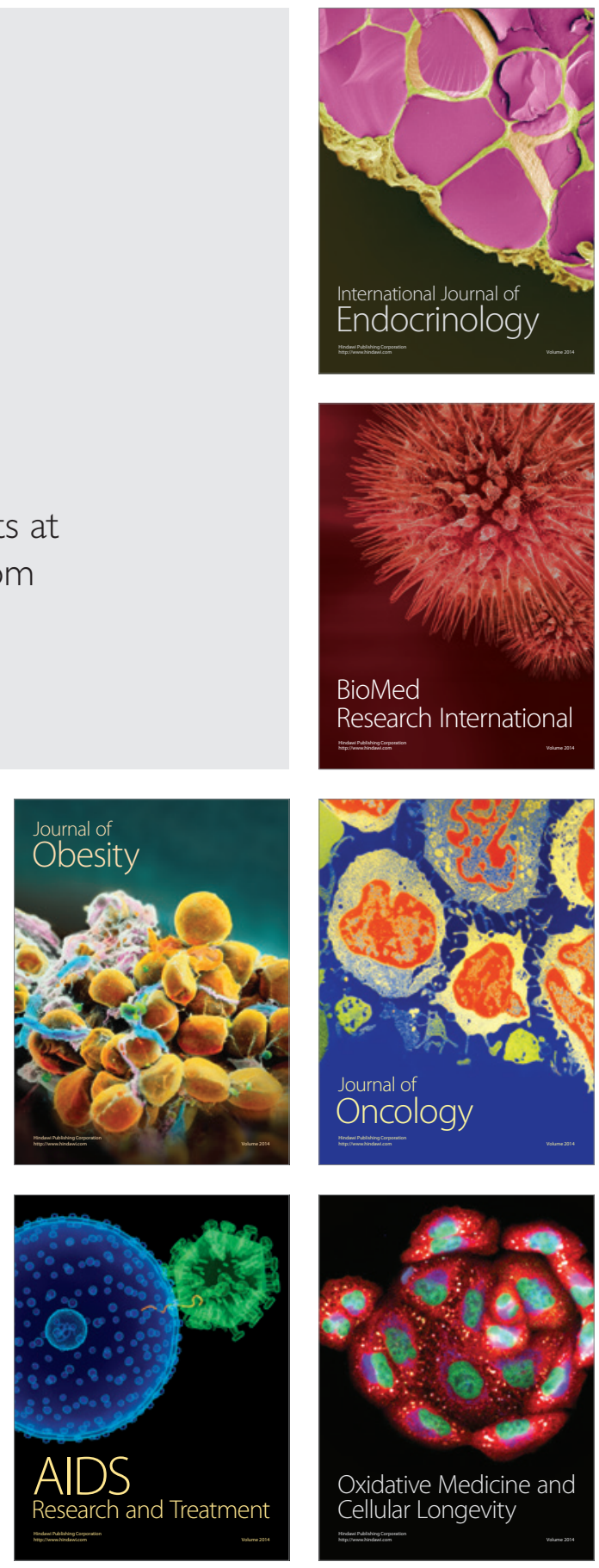